\title{
HypAir FeNO: an electrochemical sensor
}

\author{
To the Editor:
}

We would like to congratulate AlCÁZAR-NAVARrete et al. [1] on their paper which was published in a recent issue of the European Respiratory Journal. The authors observed that persistent exhaled nitric oxide fraction $(\mathrm{FeNO})$ values $\geqslant 20 \mathrm{ppb}$ in clinically stable chronic obstructive pulmonary disease (COPD) outpatients are associated with a significantly higher risk of acute exacerbations of COPD (AECOPD). This kind of approach would certainly have significant consequences for the follow-up of COPD patients.

Nevertheless, although the authors stated that FeNO was measured with a chemiluminescence nitric oxide (NO) analyser, referring to a HypAir FeNO machine (Médisoft, Sorinnes, Belgium), this device actually has electrochemical-based analysis [2].

Chemiluminescence-based analysis is considered to be the gold standard technique for measuring FeNO. These analysers are fast responding, highly sensitive and specific for nitric oxide gas. However, several factors such as size, cost and frequent calibration limit their permeation into routine clinical practice. To overcome these limitations electrochemical sensors have recently been developed and incorporated into hand-held measuring devices, but hand-held devices are not interchangeable so this information needs to be considered when these devices are used either for research purposes or for clinical practice $[3,4]$. The well-established chemiluminescence-based NIOX (Aerocrine, Solna, Sweden) analysers are much more commonly used and most of the other devices give similar results [5], but measurements on the HypAir FeNO are 1.6 times (95\% CI 1.11-2.05) higher than those obtained with the NIOX device. Therefore, a conversion factor is required if results are going to be compared with chemiluminescence devices [6] and it would be necessary if the results of the study want to be extrapolated to other centres.

A proper calibration and the possibility to show the plateau value ensure the reliability and accuracy of test results. HypAir FeNO allows real-time monitoring assuring that the value of FeNO has been obtained from manoeuvers with acceptability criteria. The manufacturer just recommends that the HypAir FeNO should be calibrated every 6 months with a $100 \mathrm{ppb} \mathrm{NO}$ gas, there are no instructions concerning regular zero calibration checking. A reliable NO-free calibration gas is essential for $\mathrm{NO}$ and the current American Thoracic Society/European Respiratory Society calibration recommendations are limited to ozone-/ $\mathrm{NO}_{2}$-chemoluminescence-based analysers [6]. LoDGe et al. [7] have developed a procedure that provides a pre-test check for the functioning of the NO scrubber in HypAir FeNO, and the paper by ALCÁZARNAVARRETE et al. [1] does not report if this has been used as a routine quality control procedure.

Cristina Ramos Hernández, Marta Núñez Fernández, Cecilia Mouronte-Roibas, Mar Mosteiro Añon and Alberto Fernández-Villar

Pulmonary Dept, University Complex of Vigo, Neumo Vigo I+i, Insttituto de Investigación Sanitaria Galicia Sur (IISGS), Vigo, Spain.

Correspondence: Cristina Ramos Hernández, University Hospital Complex of Vigo. C/ Clara Campoamor 341, 36312 Vigo, Spain. E-mail: cristina.ramos.hernandez@sergas.es

Received: Jan 242018 | Accepted: Jan 292018

Conflict of interest: None declared.

\section{References}

1 Alcázar-Navarrete B, Ruiz Rodríguez O, Conde Baena $\mathrm{P}$, et al. Persistently elevated exhaled nitric oxide fraction is associated with increased risk of exacerbation in COPD. Eur Respir J 2018; 51: 1701457.

2 Maniscalc M, Vitale C, Vatrella A, et al. Fractional exhaled nitric oxide-measuring devices: technology update. Med Dev 2016; 9: 151-160.

@ERSpublications

HypAir FeNO is an electrochemical sensor; there is no chemiluminescence NO device http://ow.ly/tmvX30irOO7

Cite this article as: Ramos Hernández C, Núñez Fernández M, Mouronte-Roibas C, et al. HypAir FenO: an electrochemical sensor. Eur Respir J 2018; 51: 1800164 [https://doi.org/10.1183/13993003.00164-2018]. 
3 Horváth I, Barnes PJ, Loukides S, et al. A European Respiratory Society technical standard: exhaled biomarkers in lung disease. Eur Respir J 2017; 49: 1600965.

4 American Thoracic Society, European Respiratory Society. ATS/ERS recommendations for standardized procedures for the online and offline measurement of exhaled lower respiratory nitric oxide and nasal nitric oxide, 2005. Am J Respir Crit Care Med 2005; 171: 912-930.

5 Korn S, Telke I, Kornmann O, et al. Measurement of exhaled nitric oxide: comparison of different analysers. Respirology 2010; 15: 203-1208.

6 Brooks CR, Brogan SM, Van Dalen CJ, et al. Measurement of exhaled nitric oxide in a general population sample: a comparison of the Medisoft HypAir FeNO and Aerocrine NIOX analyzers. J Asthma 2011; 48: 324-328.

7 Lodge CJ, Khalafzai RU, Dharmage SC, et al. Checking zero calibration of the HypAir FeNO. Am J Respir Crit Care Med 2010; 182: 719-720. 